\title{
HORAS E UNIDADES DE FRIO EM POMARES DE MAÇÃ COM DIFERENTES MICROCLIMAS ${ }^{1}$
}

\author{
HEVERLY MORAIS ${ }^{2} \&$ JULIANA CARBONIERI ${ }^{3}$
}

RESUMO- A informação da quantidade de frio em locais com microclimas distintos é um importante subsídio tecnológico para os produtores de maçã, pois reduz os custos de produção, otimiza o momento da aplicação de indutores de brotação e proporciona melhor homogeneização da brotação e frutificação, melhorando a qualidade dos frutos e fornecendo ao agricultor informações para a escolha de espécies e cultivares mais adaptadas às condições microclimáticas locais. O objetivo deste trabalho foi caracterizar os microclimas em pomares de maçã e calcular as horas de frio e unidades de frio acumuladas no período de abril a setembro de 2013, bem como avaliar a tendência e variabilidade temporal do número de horas de frio para a região sul do Paraná. Para isso, foram instaladas duas estações meteorológicas automáticas no interior de pomares de maçã, em duas localidades do município de Palmas-PR. Os registros dos dados climáticos foram obtidos de outubro de 2012 a setembro de 2013. Para a análise climatológica de horas de frio, foram utilizados dados da série histórica de 1979 a 2013 do IAPAR, provenientes de uma estação meteorológica convencional situada no município de Palmas-PR. Existem diferenças na quantidade de horas e unidades de frio acumuladas em localidades próximas, porém com microclimas distintos. Em 2013, os meses de julho e agosto foram os que apresentaram maior número de horas de frio. $\mathrm{O}$ acúmulo de unidades de frio foi semelhante entre os métodos Carolina do Norte Modificado e Utah Modificado. Há tendência temporal decadal de redução do número de horas de frio na região sul do Paraná.

Termos para indexação: Criófilas, Malus domestica, acúmulo de frio, Carolina do Norte Modificado, Utah Modificado.

\section{CHILLING HOURS AND UNITS IN APPLE ORCHARDS WITH DISTINCT MICROCLIMATE}

\begin{abstract}
The information on the amount of cold in places with distinct microclimates is an important technology subsidy for apple growers, as it reduces production costs by optimizing the time of application of induced sprouting, providing better homogenization of budding and fruiting, favoring the fruit quality and giving information to the farmer for the choice of species and cultivars most adapted to the local microclimate. The aim of this study was to characterize the microclimate in apple orchards and calculate the chilling hours and chilling units accumulated from April to September 2013, as well as evaluating the trend and temporal variability of the number of chilling hours for the South region of the State of Paraná. For that, two automatic meteorological stations were installed within apple orchards, in two locations in the municipality of Palmas, PR. The registers of climatic data were obtained from October 2012 to September 2013. For climatological analysis of chilling hours, time series data from 1979 to 2013 from a conventional meteorological station, from IAPAR, placed in the municipality of Palmas, PR, were used. There are differences in the amount of chilling hours and units accumulated in nearby localities with distinct microclimate. In 2013, July and August were the months with more chilling hours. The amount of chilling units was similar among the analyzed methods (North Caroline modified and Utah modified). There is decadal trend of reduction of chilling hours in the southern of the State of Paraná.
\end{abstract}

Index terms: Cryophilic species, Malus domestica, Amount of cold, North Caroline modified, Utah modified.

${ }^{1}$ (Trabalho 005-14). Recebido em: 14-01-2014. Aceito para publicação em: 26-03-2014.

${ }^{2}$ Engenheira Agrônoma, Pesquisadora. Instituto Agronômico do Paraná. E-mail: heverlymorais@gmail.com

${ }^{3}$ Bióloga. Instituto Agronômico do Paraná. E-mail: jucarbonieri@gmail.com 


\section{INTRODUÇÃO}

Espécies frutíferas criófilas de clima temperado com folhas caducifólias, como a macieira, apresentam um período de dormência altamente dependente das condições térmicas que, por sua vez, afetam o nível das substâncias reguladoras de crescimento que controlam as mudanças metabólicas de entrada e saída da dormência (PETRI et al., 2002). A quantidade de frio requerida para superar a dormência varia de acordo com a espécie e cultivar, sendo a macieira uma das mais exigente em frio (BRAGA; STECKERT, 1987). Algumas cultivares comerciais de maçã, como as do grupo Fuji, requererem 700 a 800 horas de frio (PETRI; PASQUAL, 1982), entretanto, o melhoramento genético busca a seleção de cultivares com menor exigência de frio, para que seu cultivo territorial seja mais amplo, como, por exemplo, a maçã Eva (IAPAR-75), que necessita de 100 a 450 horas de frio. Temperaturas insuficientes para atender às exigências das espécies, sem utilização de produtos indutores para a superação da dormência, causam anomalias fenológicas nas plantas, cujo resultado final é a redução de crescimento, desenvolvimento, rendimentos e longevidade (BURGOS; LEDESMA, 1942; PASCALE; ASPIAZÚ, 1965; CAMELATTO, 1990; MOTA, 1957).

O conhecimento do requerimento de frio de determinado local é muito importante para escolha de espécies e cultivares e determinação do momento da superação de dormência, pois em locais onde o frio é insuficiente para superar a dormência de algumas cultivares de maçã, há necessidade de aplicações de produtos químicos sintéticos para complementar seu requerimento em frio e iniciar um novo ciclo vegetativo e reprodutivo, que ocorre, normalmente, quando aproximadamente dois terços do total do requerimento em frio tenham sido acumulados (EREZ, 2000). O zoneamento agroclimático para fruteiras de clima temperado é uma excelente ferramenta para escolha de espécies e cultivares; no entanto, devido à extensa área de abrangência, na qual se desconsidera os micro e mesoclimas, fica impossibilitada uma recomendação mais acurada (BOTELHO et al., 2006). Assim, a informação da quantidade de frio acumulado, precipitação, temperatura e umidade do ar em locais com microclimas distintos é um importante subsídio tecnológico para os produtores de maçã, pois reduz custos de produção, otimiza o momento da aplicação de indutores de brotação (JACKSON, 2000), proporciona melhor homogeneização da brotação $\mathrm{e}$ frutificação, favorece melhor qualidade dos frutos, além de fornecer ao agricultor informações para a escolha de espécies e cultivares mais adaptadas às condições microclimáticas locais.

Para mensurar o requerimento de frio necessário para superar a dormência das gemas, $o$ método mais comumente utilizado é de acúmulo de Horas de Frio. Entretanto, este modelo é limitado, uma vez que não considera o acúmulo de frio para temperaturas acima de $7,2^{\circ} \mathrm{C}$ (RICHARDSON et al., 1974; SHALTOUT; UNRATH, 1983). Atualmente, existem outros modelos de estimativa de quantidade de frio como o Carolina do Norte e o Utah, cujos valores são expressos em Unidades de Frio e não consideram um valor fixo de temperatura. Estes novos modelos são mais acurados por apresentarem maior abrangência de temperaturas efetivas e incorporarem efeitos negativos para temperaturas mais elevadas, como em regiões subtropicais (PUTTI et al., 2003).

Em adição, estudos de tendências climatológicas e parâmetros de variabilidade climática são de ampla aplicação no planejamento de atividades agropecuárias, zoneamento agrícola (CARDOSO et al., 2012) e elaboração de cenários futuros.

O objetivo deste trabalho foi caracterizar os microclimas em pomares de maçã e calcular as horas de frio e unidades de frio acumuladas no período de abril a setembro de 2013, bem como avaliar a tendência e a variabilidade temporal do número de horas de frio de 1979 a 2013 para a região sul do Paraná, visando a identificar as disponibilidades climáticas e microclimáticas para a macieira.

\section{MATERIAL E MÉTODOS}

O experimento foi desenvolvido no município de Palmas-PR, cuja região é a maior produtora de maçã do Estado do Paraná (IBGE, 2012), devido às condições climáticas favoráveis. O município possui altitudes que variam de 950 a $1.400 \mathrm{~m}$ e clima Cfb, segundo a classificação de Köppen, com invernos muito frios, verões frescos e sem estação seca definida. A temperatura média do mês mais quente (janeiro) é de $20,3^{\circ} \mathrm{C}$, e a média do mês mais frio (julho) é de $11,7^{\circ} \mathrm{C}$. A precipitação média anual é de $2.110 \mathrm{~mm}$ (IAPAR, 2013).

A área experimental foi composta por dois pomares de maçã situados em localidades próximas, distanciadas em $30 \mathrm{~km}$, mas com características topoclimáticas distintas: Horizonte $\left(26^{\circ} 34^{\prime} 40,7^{\prime \prime} \mathrm{S}\right.$; $\left.51^{\circ} 46^{\prime} 01,2^{\prime \prime} \mathrm{W} ; 1260 \mathrm{~m}\right)$ e Geraldo Lovo (2631'29,7's; 5200'03,3”'W; 1149m).

Para a caracterização microclimática e a 
obtenção dos dados de temperatura para cálculo da quantidade de frio, foi instalada no interior do pomar de cada localidade uma estação meteorológica automática e registrados dados meteorológicos horários e diários no período de outubro de 2012 a setembro de 2013. As variáveis avaliadas foram: temperatura média, mínima e máxima, umidade relativa do ar e precipitação total. Os sensores de temperatura e umidade do ar foram posicionados a 2,0 m acima do solo (modelo HMP45C, ref. com. Campbell Scientific, Logan, EUA). Os pluviômetros foram instalados a 1,5 $\mathrm{m}$ de altura do solo, a 15 $m$ de distância da estação meteorológica (modelo TE525MM, ref. com. Texas Eletronics, Dallas, EUA). Os sensores foram conectados a um sistema automático de aquisição de dados (modelo CR1000, ref. com. Campbell Scientific, Logan, EUA).

Foi determinada a quantidade de frio por meio dos métodos Número de Horas de Frio (HF) e Unidades de Frio (UF), no período de 12 de abril a 30 de setembro de 2013. Para o cálculo do número de horas de frio, foram somadas as temperaturas médias horárias menores ou iguais a $7,2^{\circ} \mathrm{C}$. Para contabilizar as unidades de frio, foram utilizados os métodos Carolina do Norte Modificado e Utah Modificado. Ambos os modelos baseiam-se no acúmulo de unidades, pelo qual certa temperatura registrada por uma hora equivale a uma determinada quantidade de unidade de frio adimensional (RICHARDSON et al., 1974; SHALTOULT; UNRATH, 1983). Em tais métodos, também se adota o procedimento de restringir as unidades de frio negativas acumuladas acima de $96 \mathrm{~h}$, até o momento em que ocorrerem unidades de frio positivas (PETRI et al., 1996). Tais modelos foram adotados porque a localidade em estudo está situada numa região de clima subtropical, em que podem ocorrer altas temperaturas no inverno, que resultam em efeito negativo sobre o frio acumulado.

Foi calculado o número de horas de frio com temperatura igual ou inferior a $7,2^{\circ} \mathrm{C}$ da série histórica de 1979 a 2013, no período de abril a setembro. Para isto, foram utilizados dados da estação meteorológica convencional do Instituto Agronômico do Paraná, do município de Palmas-PR, cujas coordenadas geográficas são $26^{\circ} 28^{\prime} 05,7$ ' S; 51 ${ }^{\circ} 58$ '34,9”W; 1.100 $\mathrm{m}$. Para a análise decadal, foram considerados para a década de 80 os anos de 1981 a 1990; na década de 90, os anos de 1991 a 2000, e na década de 00, os anos 2001 a 2010. Para a comparação de períodos homogêneos, foram desconsiderados nesta análise os anos de 1979, 1980, 2011, 2012 e 2013.

\section{RESULTADOS E DISCUSSÃO}

Quanto à caracterização microclimática, não ocorreram diferenças marcantes no regime pluviométrico para as duas localidades estudadas. As pequenas diferenças que ocorreram podem ser atribuídas à variabilidade espacial, natural da precipitação (Figura 1). As localidades em estudo são distanciadas $30 \mathrm{~km}$ entre si, sendo frequentes pancadas de chuvas isoladas em regiões próximas. Nota-se que as maiores diferenças entre as duas localidades ocorreram em meses em que os níveis de precipitação foram mais elevados. Em ambas as localidades, o mês de novembro de 2012 destacouse por apresentar precipitações abaixo da média histórica, e os meses de março e junho de 2013 tiveram valores acima. Não foi registrada tendência temporal de precipitação ao longo do período analisado. Ocorreram falhas no funcionamento dos pluviômetros no mês de julho, cujos dados não constam nos resultados deste trabalho. O clima da região em estudo foi descrito por Köppen como $\mathrm{Cfb}$, ou seja, as precipitações são distribuídas ao longo do ano, sem estação seca definida. Mellart (1999) relata que a distribuição da precipitação depende da topografia local e do tipo de chuva, encontrando diferenças na variabilidade espacial das chuvas para distâncias relativamente pequenas (na ordem de $1 \mathrm{~km}$ ). Entretanto, o mesmo ressalta que o grau de variabilidade ocorre de acordo com o ano e a região. Utilizando dados diários de precipitação pluvial de 19 estações meteorológicas do Estado de São Paulo, Camargo et al. (2001) concluíram que há variabilidade espacial nas precipitações, especialmente a partir de $20 \mathrm{~km}$ e nos meses de verão, quando há predomínio de chuvas convectivas. Bega et al. (2005) constataram variabilidade espacial nas precipitações diárias, em uma escala reduzida, em Pindorama-SP, em um período de 32 anos, utilizando dados de cinco pluviômetros, cujas distâncias entre si variavam de 257 a 3.900 m. Os autores concluíram que pluviômetros próximos, porém sob maiores variações de altitude, possuem diferenças superiores a pluviômetros mais distantes, mas sob altitudes similares.

Para a temperatura do ar, observa-se que as mínimas registradas em agosto foram menores na localidade Horizonte, em comparação a Geraldo Lovo (Figura 2A). Isto ocorreu devido à altitude, uma vez que Horizonte está situada a $111 \mathrm{~m}$ acima de Geraldo Lovo. A altitude é um fator determinante na variação da temperatura, sendo estas inversamente proporcionais. Analisando o mês mais quente do município (janeiro), observa-se que as temperaturas 
máximas foram diferentes nas duas localidades em estudo, sendo que Geraldo Lovo apresentou médias mais elevadas (Figura 2B). Isto ratifica os resultados obtidos no período de temperaturas amenas (Figura 2A), reflexo da maior altitude na localidade Horizonte. De acordo com Cargnelutti Filho et al. (2006), a altitude e a latitude, nesta ordem, exercem maior efeito sobre a temperatura mínima média decendial do ar no Estado do Rio Grande do Sul.

Analisando as diferenças entre as temperaturas médias mensais, observa-se que, na localidade Horizonte, registraram-se valores entre $4,4^{\circ}$ e $1,0^{\circ} \mathrm{C}$ menores que a estação Geraldo Lovo, o que pode ser atribuído à maior altitude naquela localidade (Tabela 3). Comparando as temperaturas médias de duas localidades do Estado do Paraná, distantes $20 \mathrm{~km}$ entre si, Paiva et al. (2011), constataram que em todos os meses do ano as menores temperaturas médias foram registradas em Floraí-PR, onde predominam altitudes entre 500 e $550 \mathrm{~m}$, e que os maiores valores foram encontrados em São Carlos do Ivaí-PR, que possui altitudes de 250 a 300 m. Fritzsons et al. (2008) concluíram que, no Estado do Paraná, a altitude apresenta uma influência maior sobre a temperatura média anual, média anual de julho e média anual de janeiro, comparada à longitude e à latitude.

Observa-se que Horizonte, a localidade mais fria, apresentou maior umidade relativa nas horas de ocorrência das menores temperaturas (Figura 3). Como a umidade relativa é inversamente proporcional à temperatura do ar, se o ar não está saturado de vapor d'água e se não ocorrer precipitação, este efeito intensifica-se.

Houve diferenças nas quantidades de horas e unidades de frio acumuladas entre as localidades analisadas, devido à altitude e ao relevo local (Figura 4). Na localidade Horizonte, com maior altitude, houve acúmulo de $40 \%$ mais de horas de frio que em Geraldo Lovo. Quanto às unidades de frio, as diferenças entre as localidades foram mais pronunciadas, sendo $59 \%$ maior na localidade Horizonte. A altitude pode ser considerada como o fator que determinou este contraste, pois as temperaturas mais baixas na localidade mais alta contabilizaram a maior quantidade de unidades de frio, enquanto as temperaturas mais altas na localidade mais baixa proporcionaram menos unidades de frio, ou até unidades de frio negativas em abril e maio (Figura 5). Isto evidencia a necessidade de medições meteorológicas em locais com topoclimas distintos para a obtenção de parâmetros agrometeorológicos, como número de horas de frio e unidades de frio, mais acuradas. Iuchi et al. (2002) afirmam que, no município de São Joaquim-SC, somente nos locais altos, acima de $1.300 \mathrm{~m}$, em anos acima de 2.300 unidades de frio, é dispensada a superação de dormência artificial para as cultivares de macieiras do grupo Gala. Botelho et al. (2006) concluíram que as regiões paranaenses indicadas como aptas, para o cultivo de fruteiras de clima temperado com maior exigência em frio, possuem diferentes quantidades de frio acumuladas, devido às suas características climáticas e orográficas distintas. Heldwein et al. (2000) verificaram discreto aumento na quantidade de horas de frio abaixo de $7^{\circ} \mathrm{C}$ na direção oeste da Depressão Central do RS, e isso foi atribuído ao aumento da altitude e/ou continentalidade. Entretanto, os autores afirmaram que as diferenças de altitude entre os locais não tiveram a influência esperada sobre a disponibilidade de frio na região, demonstrando que, além da altitude, possivelmente, a continentalidade, fatores locais e outros não identificados tiveram grande influência. Em estudos sobre a distribuição geográfica das horas de frio no Estado do Rio Grande do Sul, Buriol et al. (2000) observaram os menores valores em locais de menor altitude, como no vale dos Rios Jacuí, Vacacaí, Ibicuí e seus afluentes, e valores mais elevados nos locais de maior altitude, como no Planalto e na Serra do Sudeste. Segundo Braga et al. (2001),para a elaboração do zoneamento de riscos climáticos para a cultura da maçã em Santa Catarina, regiões com menores altitudes do Estado não foram recomendadas para a cultura, devido à alta correlação desta com a quantidade de horas de frio necessária para a superação da dormência das gemas. De acordo com Matzenauer et al. (2007), a região do Planalto Superior do Estado do Rio Grande do Sul, a qual apresenta maior altitude, foi a que registrou maior quantidade de horas de frio acumulada abaixo de $7^{\circ} \mathrm{C}$, em todos os meses do ano e, inclusive, foi a única região que apresentou o acúmulo de uma hora de frio no verão.

Na Figura 6, são apresentados os dados mensais de horas de frio para as duas localidades em estudo, bem como a média histórica. Observa-se que os meses em que houve maior acúmulo de horas de frio, em 2013, foram julho e agosto, enquanto o maior acúmulo ocorreu em junho e julho. A localidade Horizonte superou, em acúmulo de horas de frio, a localidade Geraldo Lovo, na média histórica de todos os meses, devido à sua maior altitude. Os meses de abril e setembro foram os que acumularam menor quantidade de frio. Avaliando vinte e seis localidades do Estado Rio Grande do Sul, Matzenauer et al. (2005) encontraram valores mais elevados de horas de frio 
no período de junho a agosto, sendo julho o mês mais frio entre a maioria das localidades analisadas e maio e setembro os meses de menor número de horas de frio. Heldwein et al. (2000) analisaram a quantidade de horas de frio, considerando os limites de 7 e $13^{\circ} \mathrm{C}$, nos meses de abril a outubro, em diversas localidades da região central do Rio Grande do Sul, e verificaram que, na segunda quinzena do mês de setembro, houve decréscimo acentuado na ocorrência de horas de frio abaixo de $7^{\circ} \mathrm{C}$ em todas as localidades.

Comparando o total de unidades de frio (UF) pelos métodos Carolina do Norte Modificado e Utah Modificado para as localidades analisadas, observase que houve pequenas variações entre os métodos (Figura 7). Isto demonstra precisão e confiabilidade destes modelos, que são alternativas adequadas para cálculos de unidades de frio. Entretanto, Botelho et al. (2006) encontraram diferenças de aproximadamente $50 \%$ entre Carolina do Norte modificado e Utah modificado, para quatro municípios do Paraná: Palmas, Ponta Grossa, Curitiba e Guarapuava, nos anos de 2000 a 2004. Biasi et al. (2010) calcularam a quantidade de horas de frio abaixo de $7,2^{\circ} \mathrm{C}$ e unidades de frio, pelo método Utah tradicional e modificado, nos anos de 2007 e 2008, em Pinhais-PR. Segundo os autores, pelo método Utah tradicional houve um somatório negativo nos dois anos avaliados, evidenciando períodos de outono e inverno com muitas horas de temperaturas acima de $16^{\circ} \mathrm{C}$, que anularam o efeito do frio acumulado. Para o método Utah modificado, que limita o efeito negativo das temperaturas mais elevadas, os autores observaram acúmulo positivo de unidades de frio.

Analisando o número de horas de frio (HF) da série histórica de dados entre 1979 e 2013, observa-se a variação de 267 (1998) a 713 HF (1979) (Figura 8). Nota-se que o acúmulo do número de horas de frio apresentou grande variabilidade a cada ano. No entanto, sob análise decadal (década de 1980, 1990 e 2000), observa-se que houve tendência temporal de diminuição do número de horas de frio, registrando na década de 1980 o total de $4.828 \mathrm{HF}$, e nas décadas de 1990 e $2000,4.273$ e $4.128 \mathrm{HF}$, respectivamente (Figura 8).

Observa-se que 2013 foi um ano intermediário de acúmulo de horas de frio, com valores de apenas 11\% acima da média histórica. Botelho et al. (2006), analisando o acúmulo de horas de frio e unidades de frio para as diversas regiões do Estado do Paraná Curitiba, Palmas, Guarapuava e Ponta Grossa - no período de 2000 a 2004, observaram que o município de Palmas foi o que apresentou valores mais altos de quantidade de frio. Quantificando o frio em São Joaquim-SC, a $1.415 \mathrm{~m}$ de altitude, Iuchi et al.
(2002) encontraram, no ano de 1998, registros de $772 \mathrm{HF}$, enquanto no ano 1999 foram acumuladas 1.005 HF. Cardoso et al. (2012) observaram em Vacaria-RS, na série de 1983 a 2009, os menores acúmulos de HF a partir de 2000, especialmente em 2002, 2005, 2006 e 2008. Em estudos de análise da variabilidade temporal da temperatura do ar na América do Sul, utilizando dados de temperaturas médias diárias de 1948 a 2006, Marques e Diniz (2007) encontraram tendência de aumento na temperatura em praticamente todo o continente Sul Americano. João (2009) também encontrou tendência de aumento nas temperaturas mínimas, no Estado do Rio Grande do Sul, na série histórica de 1918 a 2007. Segundo Cardoso et al. (2012), a redução do acúmulo de frio pode estar relacionada com o aumento das temperaturas mínimas, como demonstrado por Marengo e Camargo (2008), Pereira et al. (2009) e Cordeiro (2010), tanto em escala global quanto em regional. 
TABELA 1- Temperatura média mensal e respectivas diferenças para duas localidades do município de Palmas-PR, no período de outubro de 2012 a setembro de 2013.

\begin{tabular}{cccc}
\hline Localidade & Horizonte (A) & Geraldo Lovo (B) & Diferença (A-B) \\
\hline Outubro & 14,8 & 17,3 & 2,5 \\
Novembro & 16,6 & 18,7 & 2,1 \\
Dezembro & 19,0 & 20,5 & 1,5 \\
Janeiro & 17,2 & 18,9 & 1,7 \\
Fevereiro & 17,4 & 19,0 & 1,6 \\
Março & 12,4 & 16,7 & 4,4 \\
Abril & 12,8 & 15,7 & 2,8 \\
Maio & 11,6 & 13,2 & 1,6 \\
Junho & 10,1 & 11,9 & 1,8 \\
Julho & 10,5 & 12,4 & 1,9 \\
Agosto & 10,4 & 12,7 & 2,3 \\
Setembro & 12,9 & 13,9 & 1,0 \\
\hline
\end{tabular}

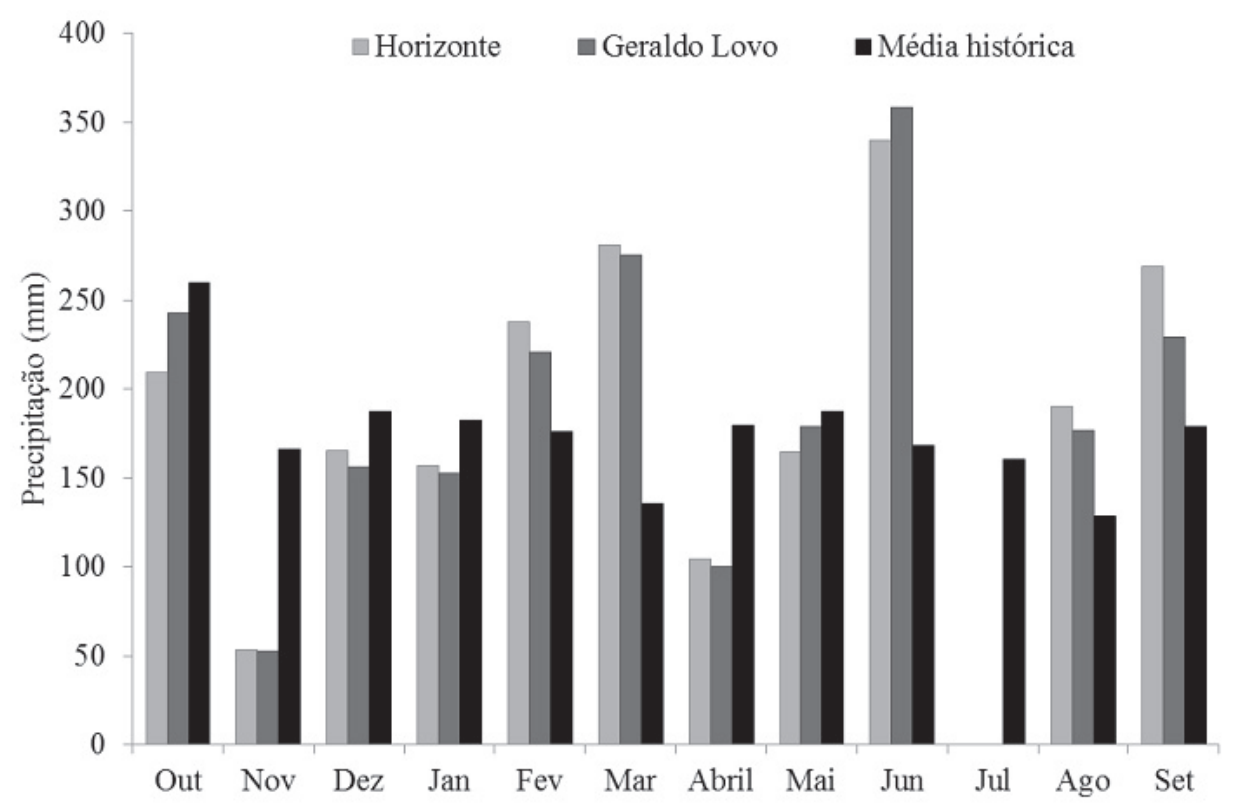

FIGURA 1- Precipitação mensal em duas localidades do município de Palmas-PR, no período de outubro/2012 a setembro/2013 e média histórica (1979-2013). 


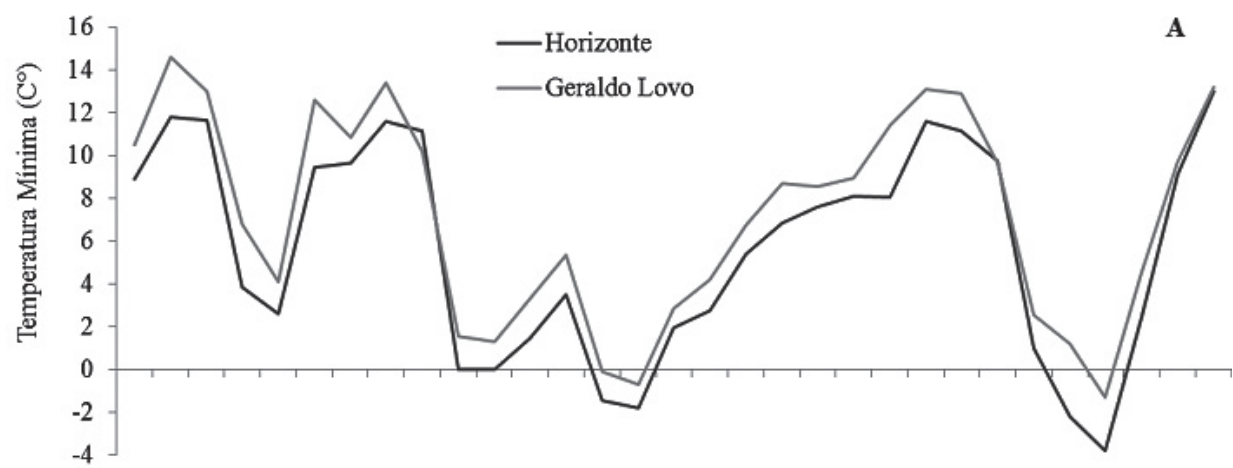

$1 \quad 2 \quad 3 \quad 4 \quad 5 \quad 6 \quad 7 \quad 8 \quad 9 \quad 10111213141516171819202122232425262728293031$ Dia

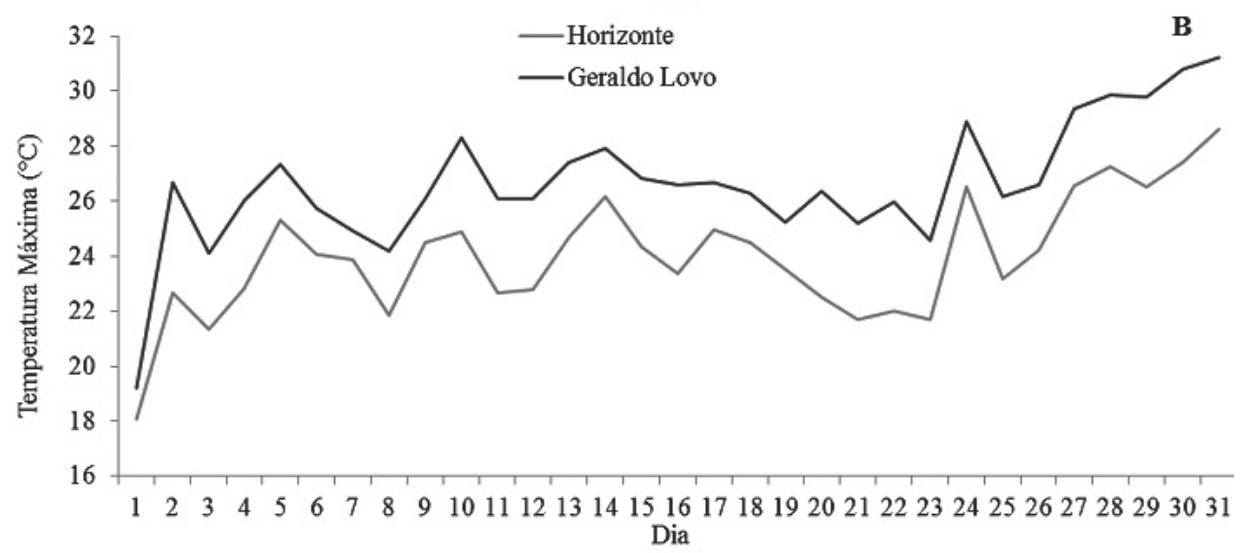

FIGURA 2 -Temperatura mínima diária de agosto (A) e máxima diária de janeiro (B), em duas localidades do município de Palmas-PR, 2013.

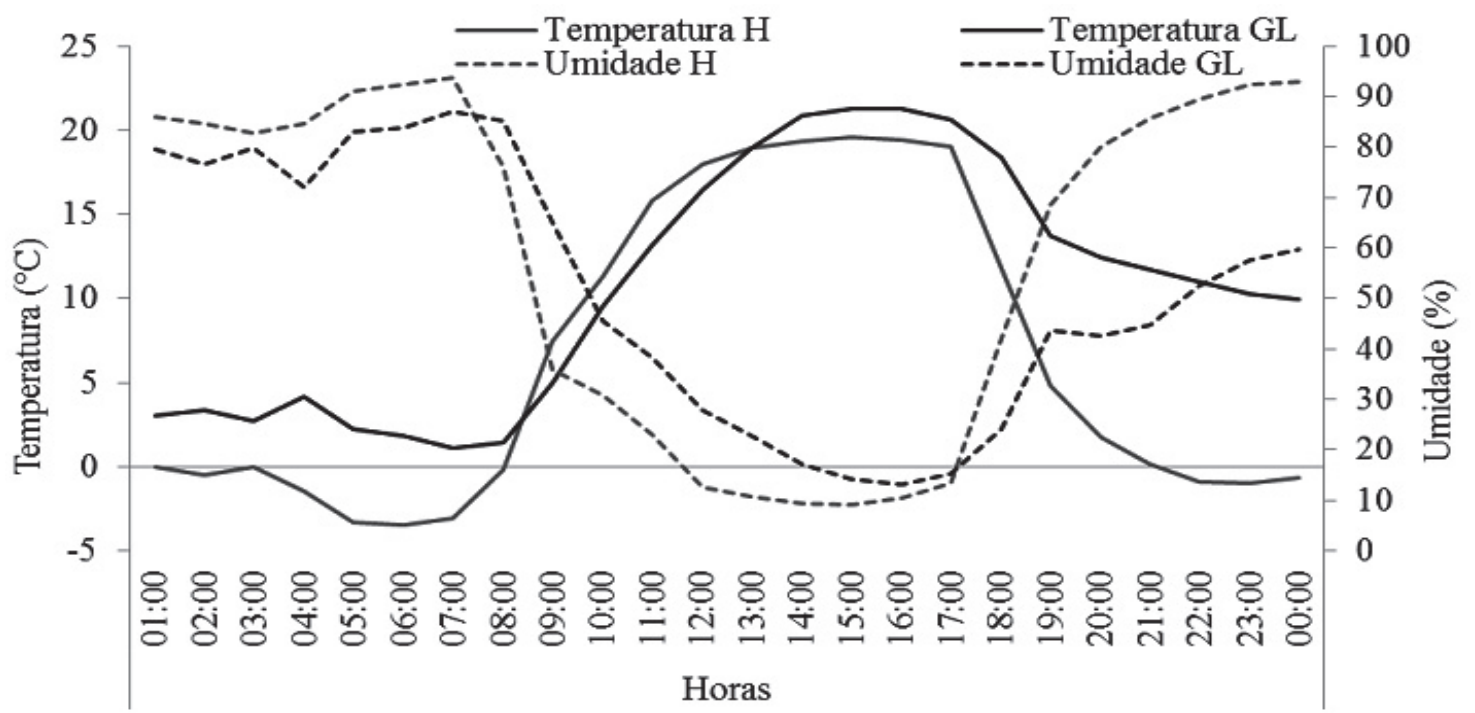

FIGURA 3- Umidade relativa e temperatura do ar no dia 8 de maio, em duas localidades do município de Palmas-PR, 2013, H (localidade Horizonte) GL (localidade Geraldo Lovo). 


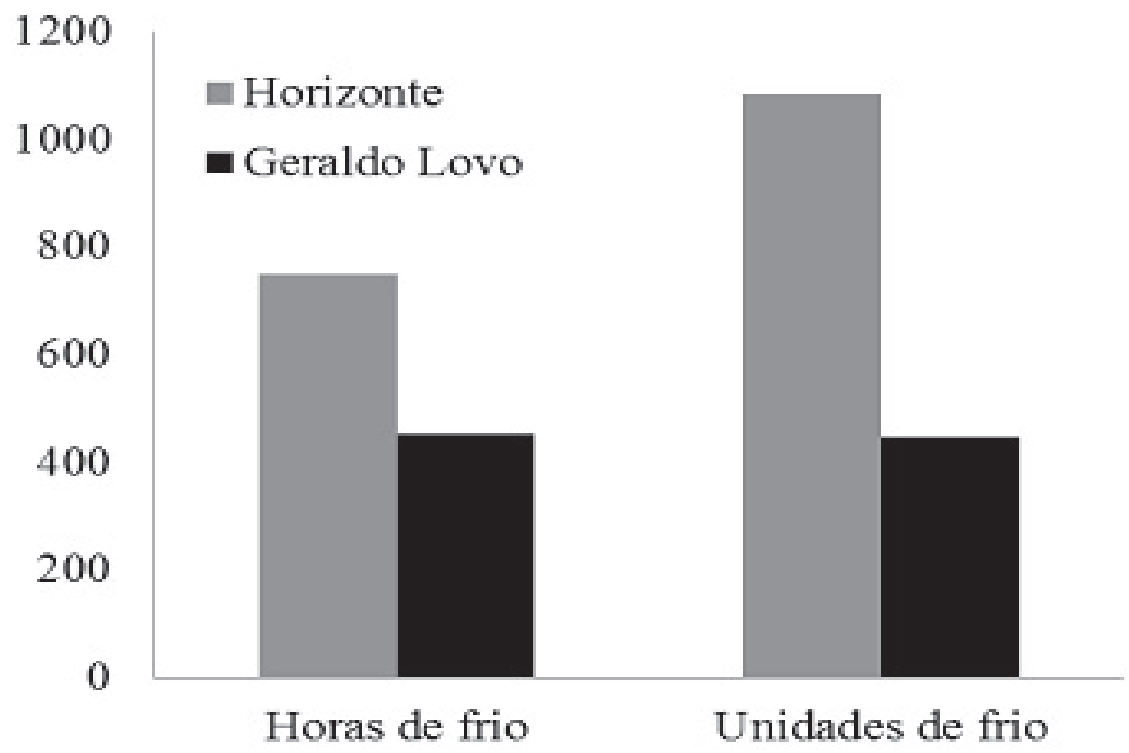

FIGURA 4- Acúmulo total de horas de frio $\leq 7,2^{\circ} \mathrm{C}$ e unidades de frio calculadas pelo método Carolina do Norte modificado, em duas localidades no município de Palmas-PR, no período de abril a setembro de 2013.

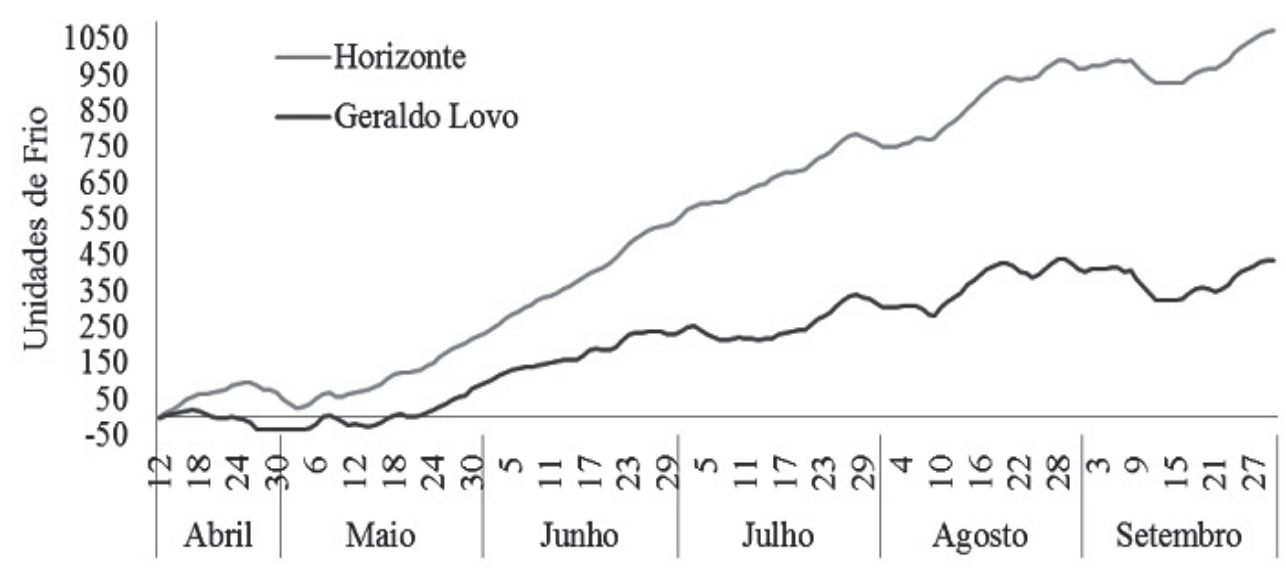

FIGURA 5- Acúmulo diário de unidades de frio calculadas pelo método Carolina do Norte modificado, em duas localidades no município de Palmas-PR, no período de abril a setembro de 2013. 


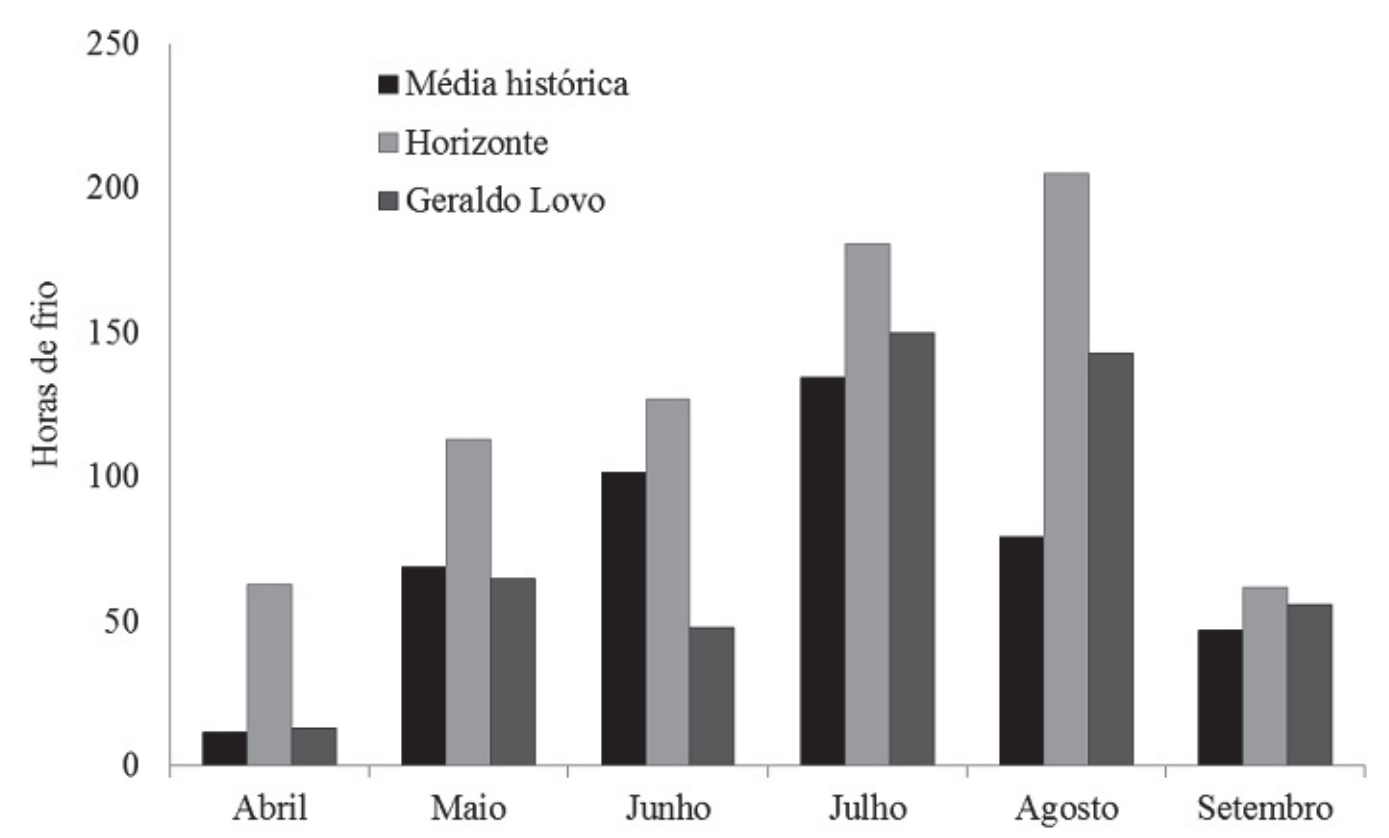

FIGURA 6- Acúmulo mensal de horas de frio $\leq 7,2^{\circ} \mathrm{C}$, em duas localidades no município de Palmas-PR, no ano de 2013, e média histórica (1979-2013) nos meses de abril a setembro.

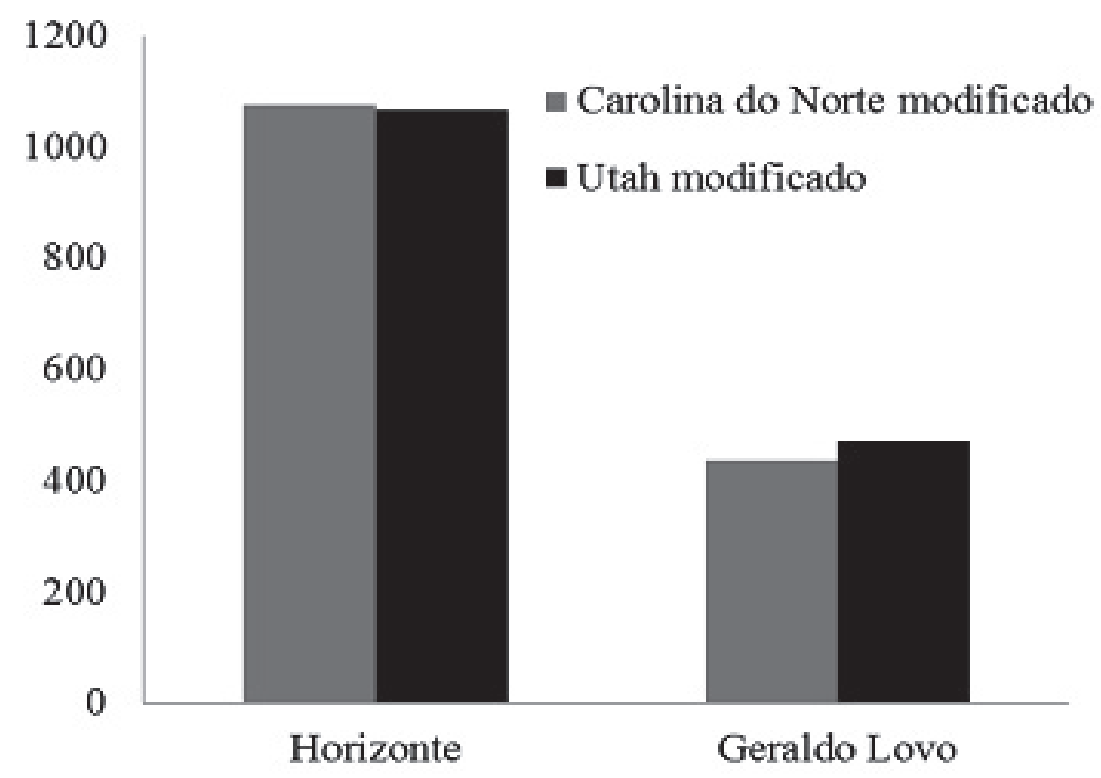

FIGURA 7- Acúmulo de unidades de frio calculadas pelos métodos Carolina do Norte Modificado e Utah Modificado, em duas localidades de Palmas-PR, no período de abril a setembro de 2013. 


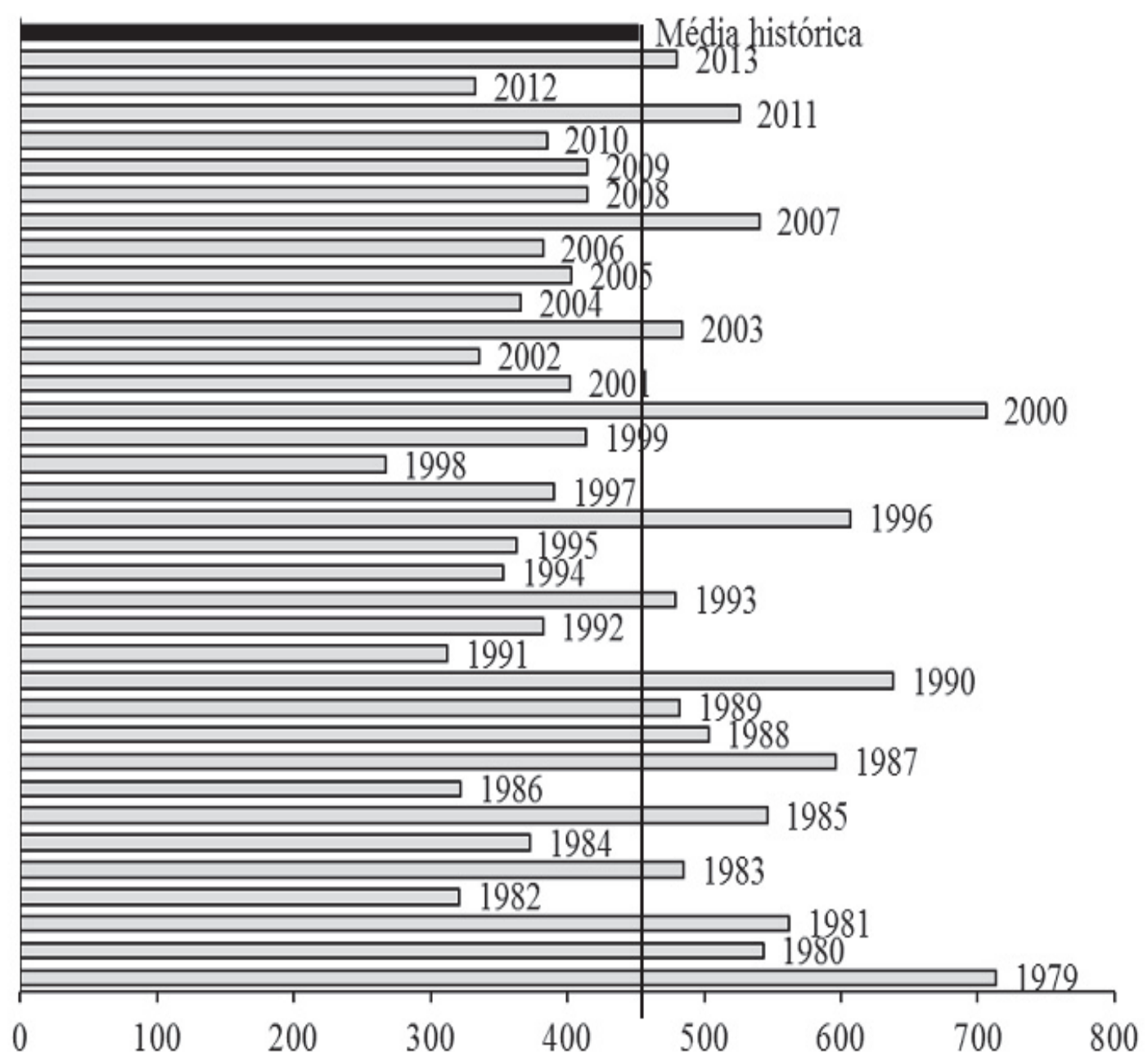

FIGURA 8- Histórico do acúmulo de horas de frio $\leq 7,2^{\circ} \mathrm{C}$ para o município de Palmas-PR, no período de 1979 a 2013, nos meses de abril a setembro.

\section{CONCLUSÃO}

O conhecimento do microclima local é fundamental para uma condução eficiente da macieira. Existem diferenças na quantidade de horas e unidades de frio acumuladas em localidades próximas, porém com microclimas distintos. Há tendência temporal decadal de redução do número de horas de frio na região sul do Paraná.

\section{REFERÊNCIAS}

BEGA, R.M.; SIDNEY ROSA VIEIRA, S.R.; MARIA, I.C.; DECHEN, S.C.F.; CASTRO, O.M. Variabilidade espacial das precipitações pluviais diárias em uma estação experimental, em PindoramaSP. Bragantia, Campinas, v.64, n.1, p.149-156, 2005.

BIASI, L.A.; CARVALHO, R.I.N.; ZANETTE, F. Dinâmica da dormência de gemas de videira e quivizeiro em região de baixa ocorrência de frio. Revista Brasileira de Fruticultura, Jaboticabal, v.32, n.4, p.1244-1249, 2010. 
BOTELHO, R.V.; AYUB, R.A.; MÜLLER, M.M.L. Somatória de horas de frio e de unidades de frio em diferentes regiões do Estado do Paraná. Scientia Agraria, Curitiba, v.7, n.1/2, p.89-96, 2006.

BRAGA, H.J.; SILVA Jr., V.P.; PANDOLFO, C.; PEREIRA, E.S. Zoneamento de riscos climáticos da cultura da maçã no Estado de Santa Catarina. Revista Brasileira de Agrometeorologia, Santa Maria, v.9, n.3, p.439-445, 2001.

BRAGA, H. J.; STECKERT, R. Estimativa de horas de frio abaixo de $7,2^{\circ} \mathrm{C} \mathrm{e} 13^{\circ} \mathrm{C}$ para 10 localidades do Estado de Santa Catarina. Florianópolis: EMPASC, 1987. 42p. (Documentos, 90).

BURGOS, J.J.; LEDESMA, N.R. Anomalias fenológicas en los árboles frutales durante el año 1939. Revista Argentina Agronomia, Buenos Aires, v.9, p.295-309, 1942.

BURIOL, G.A.; HELDWEIN, A.B.; SCHNEIDER, F.M.; ESTEFANEL, V.; OLIVEIRA, H.T.; DIDONÉ, M.A. Disponibilidade de horas de frio na região central do Rio Grande do Sul: 2 - Distribuição geográfica. Ciência Rural, Santa Maria, v.30, n.5, p.755-759, 2000 .

CAMARGO, M.B.P.; BRUNINI, O.; PEDRO JÚNIOR, M. J.; BRDIN, L. Variabilidade espacial e temporal de dados termopluviométricos diários da rede de estações meteorológicas do Instituto Agronômico. In: CONGRESSO BRASILEIRO DE AGROMETEOROLOGIA, 12., 2001, Fortaleza. Anais... Fortaleza: Sociedade Brasileira de Agrometeorologia, 2001. v.1, p.207-208.

CAMELATTO, D. Dormência em fruteiras de clima temperado. Revista Horticultura Sul, Pelotas, v.1, n.3, p.12-17, 1990.

CARDOSO, L.S.; BERGAMASCHI, H.; BOSCO, L.C.; PAULA, V.A.; MARODIN, G.A.B.; CASAMALI, B.; NACHTIGALL, G.R. Disponibilidades climáticas para a região de Vacaria-RS. Ciência Rural, Santa, Maria, v.42, n.11, p.1960-1967, 2012.

CARGNELUTTI FILHO, A.; MALUF, J.R.T.; MATZENAUER, R.; STOLZ, A.P. Altitude e coordenadas geográficas na estimativa da temperatura mínima média decendial do ar no Estado do Rio Grande do Sul. Pesquisa Agropecuária Brasileira, Brasília, v.41, n.6, p.893-901, 2006.
CORDEIRO, A.P.A. Tendências climáticas das variáveis meteorológicas originais, estimadas e das derivadas do balanço hídrico seriado do Rio Grande do Sul. 2010. 274f. Dissertação (Mestrado em Fitotecnia) - Universidade Federal do Rio Grade do Sul, Porto Alegre, 2010.

EREZ, A. Bud dormancy; phenomenon, problems and solutions in the tropics and subtropics. In: EREZ, A. Temperate fruit crops in warm climates. The Netherlands: Kluwer Academic Publishers, 2000. p.17-48.

FRITZSONS, E.; MANTOVANI, L.E.; AGUIAR, A.V. Relação entre altitude e temperatura: uma contribuição ao zoneamento climático no Estado do Paraná. Revista de Estudos Ambientais, Blumenau, v.10, n.1, p.49-64, 2008.

HELDWEIN, A.B.; SCHNEIDER, F.M.; BURIOL, G.A.; ESTEFANEL, V.; PRESTES, S.D. Disponibilidade de horas de frio na região central do Rio Grande do Sul: 1 - Ocorrência de valores acumulados para diferentes níveis de probabilidade. Ciência Rural, Santa Maria, v.30, n.5, p.747-754, 2000 .

IAPAR. Médias históricas em estações do IAPAR. 2013. Disponível em: http://www.iapar.br/arquivos/ Image/monitoramento/Medias Historicas/Palmas. htm Acesso em: jul. 2013.

IBGE. Sistema IBGE de Recuperação Automática - SIDRA. 2012. Disponível em: http://www.sidra. ibge.gov.br. Acesso em: out . 2013.

IUCHI, V.L.; IUCHI, T.; BRIGHENTI, E.; DITRICH, R. Quebra da dormência da macieira (Malus domestica Borkh) em São Joaquim - SC. Revista Brasileira de Fruticultura, Jaboticabal, v.24, n.1, p.168-174, 2002.

JACKSON, J.E. Apple production at low latitudes. In: EREZ, A. Temperate fruit crops in warm climates. The Netherlands: Kluwer Academic Publishers, 2000. p.305-342.

JOÃO, M.M. Análise do comportamento das temperaturas máxima e mínima médias mensais para o Estado do Rio Grande do Sul. 2009. 136 f. Dissertação (Mestre em Ciências) - Universidade Federal de Pelotas, Pelotas, 2009. 
MARENGO, J.A.; CAMARGO, C.C. Surface air temperature trends in Southern Brazil for 1960-2002. International Journal of Climatology, Malden, v.28, n.7, p.893-904, 2008.

MARQUES, J.R.; DINIZ, G.B. Variabilidade temporal da temperatura do ar na América do Sul e seus efeitos na precipitação durante o verão no Rio Grande do Sul. In: CONGRESSO BRASILEIRO DE AGROMETEOROLOGIA, 15., 2007, Aracaju. Anais... Aracaju: Sociedade Brasileira de Agrometeorologia, 2007. CD-ROM.

MATZENAUER, R.; BUENO, A.C.; CARGNELUTTI FILHO, A.; DIDONÉ, I.A.; MALUF, J.R.T.; HOFMAN, G.; TRINDADE, J.K.; STOLZ, A.; SAWASATO, J.T.; VIANA, D.R. Horas de frio no Estado do Rio Grande do Sul. Pesquisa Agropecuária Gaúcha, Porto Alegre, v.11, n.1-2, p.71-76, 2005.

MATZENAUER, R.; BUENO, A.C.; MALUF, J.R.T.; WREGE, M.S.; VIANA, D.R.; SANTOS, M.; CUNHA, L.F. Regime anual e estacional de horas de frio no Estado do Rio Grande do Sul. Pesquisa Agropecuária Gaúcha, Porto Alegre, v.13, n.1-2, p.11-16, 2007.

MELLART, E.A.R. Small-scale spatial rain distribution: the effect of temporal and spatial rain distribution on drought and crop yield at village level. Nelspruit: Institute for Soil, Climate and Water, 1999. 18p.

MOTA, F.S. Os invernos de Pelotas-RS, em relação às exigências de frio das frutíferas de clima temperado. Porto Alegre: Instituto Agronômico do Sul, 1957. 38p. (Boletim Técnico, 18).

PAIVA, R.G.; SILVEIRA, H.; BALDO, M.C. Variação espacial da temperatura média na escala topoclimática nos municípios de São Carlos do Ivaí e Floraí-PR. Boletim de Geografia, Maringá, v.29, n.1, p.147161, 2011.
PASCALE, A. J.; ASPIAZÚ, C. Régimen de horas de frio durante el invierno en Buenos Aires. Revista de la Faculdad de Agronomia y Veterinária de Buenos Aires, Buenos Aires, v.16, n.2, p.63-82, 1965.

PEREIRA, T.P.; FONTANA, D.C.; BERGAMASCHI, H. O clima da região dos Campos de Cima da Serra, Rio Grande do Sul: condições térmicas e hídricas. Pesquisa Agropecuária Gaúcha, Porto Alegre, v.15, n.2, p.145-157, 2009.

PETRI, J.L.; PALLADINI, J.A.; POLA, A.C. Dormência e indução da brotação da macieira. In: EPAGRI. A cultura da macieira. Florianópolis, 2002. p.261-298.

PETRI, J.L.; PALLADINI, L.A.; SCHUCK, E.; DUCROQUET,J.H.J.; MATOS, C.S.; POLA, A.C. Dormência e indução da brotação de fruteiras de clima temperado. Florianópolis: Epagri, 1996. 110p.

PETRI, J.L.; PASQUAL, M. Quebra de dormência em macieira. Florianópolis: EMPASC, 1982. 54p. (Boletim Técnico, 18).

PUTTI, G.L.; PETRI, J.L.; MENDEZ, M.E. Efeito da intensidade do frio no tempo e porcentagem de gemas brotadas em macieiras. Revista Brasileira de Fruticultura, Jaboticabal, v.25, n.2, p.199-202, 2003.

RICHARDSON, E.A.; SEELEY, S.D.; WALKER, D.R. A model for estimating the completion of rest for Redhaven and Elberta peach trees. HortScience, Alexandria, v.9, p.331-332, 1974.

SHALTOUT, A.D.; UNRATH, C.R. Rest completion prediction model for Starkrimson Delicious apples. HortScience, Alexandria, v.108, n.6, p.957-961, 1983. 